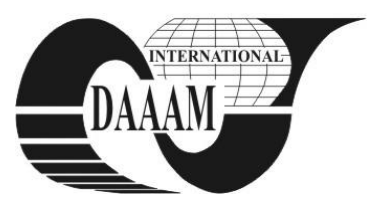

Annals of DAAAM for 2012 \& Proceedings of the 23rd International DAAAM Symposium, Volume 23, No.1, ISSN 2304-1382 ISBN 978-3-901509-91-9, CDROM version, Ed. B. Katalinic, Published by DAAAM International, Vienna, Austria, EU, 2012 Make Harmony between Technology and Nature, and Your Mind will Fly Free as a Bird Annals \& Proceedings of DAAAM International 2012

\title{
MICRORAMAN ANALYSES OF EPOXY CROSS-LINKING REACTION
}

\author{
VASKOVA, H[ana]
}

\begin{abstract}
Epoxy based materials find a number of applications. Suitability of these materials demands the process of crosslinking, which among others influences the final mechanical and thermal properties. Raman spectroscopy is a modern research and analytical tool providing specific information of a molecular structure. Prime advantages of Raman spectroscopy are non-destructivness, rapidity, contactless, no special requrements for sample preparation and others. The essence of the vibrational method along with the methodö benefits yields interesting possibilities for applying in almost all natural sciences and technical and industrial disciplines. This paper is focused on using Raman microspectroscopy as an innovative method for monitoring and analyses of epoxy resin cross-linking reaction. The study of the proccess comprises principal chemical bonds identification, their localisation in Raman spectra and their time behaviour.Experimantal data demonstrate the changesin structure during the crosslinking reaction. In regard of the rapidity of measurement a quasi real time monitoring of epoxides curing is feasible.
\end{abstract}

Keywords:Raman spectroscopy, epoxy resin, crosslinking, curing reaction, Raman spectra

\section{INTRODUCTION}

When dealing with history, it is customary to mark great epoch of mankind according to the prevalent material that served the human purposes. Speaking about the Stone Age, Bronze Age, Iron Age - the time we live in could be rightly specified as 'Polymer Age' in this sense.

Epoxy based materials are one of the most versatile polymers that are owing to their many good to excellent properties intensively used in a wide range of various technical applications. Epoxies are noted for a very good adhesion and mechanical properties as high strength and stiffness, excellent electrical properties, also resistance to thermal, moisture and mechanical shock. These properties predetermine epoxy resins to be used as adhesives and coatings, in electronics industry as electrical insulators, in industrial tooling, in aerospace and marine industry. Epoxy resins belong among materials often used in arts offering artists multifarious utilization. Those epoxy materials responsive to ultraviolet light are applied in dentistry, optoelectronics or fibre optics.

The process of crosslinking refers to linking polymer chains into a spatial network. It appears both in synthetic polymer chemistry and in the biological sciences e.g. crosslinking of proteins or collagen fibrils in tissues. Linking a polymer chains influence their ability to move what affects mechanical and thermal properties and state of matter. The process of crosslinking can be running in many ways. Cross-links are usually induced by chemical reactions. Very progressive method is radiation crosslinking using high-energy ionizing radiation. One of the benefits of using the radiation crosslinking is that the degree of crosslinking is easy to control by the amount of radiation dose. Modification of microhardness of polyamide 12 after beta irradiation is presented in papers $[1,2]$. Authors of [3] introduce the results of changes of thermo-mechanical properties of HDPE.

To acquire an epoxy resin in required qualities, i. e. as a hard and infusible material, it is needful to cure the resin, a low-molecular-weight polymer containtg epoxy groups, with a curing agent the hardener. During a curing process chemical epoxide groups in epoxy resin are crosslinked with hardener's reactive groups and a highly crosslinked three-dimensional network is formed from the initial liquid mixture. The process is illustrated in Fig. 1. A special molecular structure of epoxy group, also known as oxirane group, see Fig. 2, enables an easy participation in the addition reactions through opening the three-membered ring consisting of two carbons and one oxygen atom, and thus it easily polymerizes

The commonly used curing agents for epoxies include amines, polyamides, phenolic resins, anhydrides orisocyanates. [4].

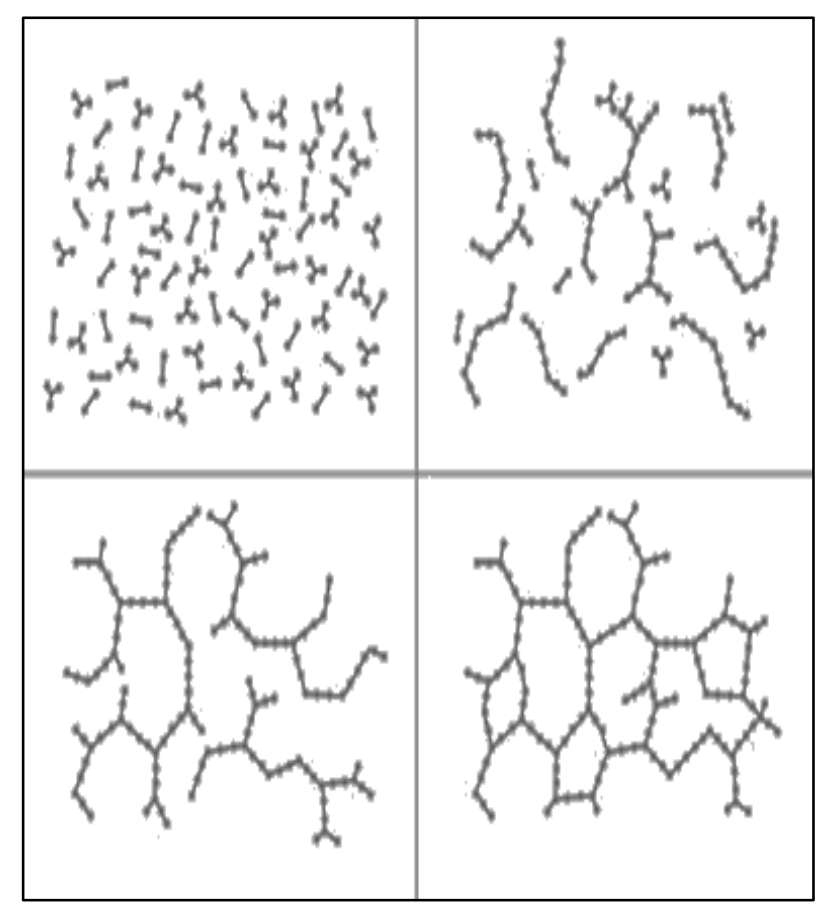

Fig. 1. Scheme of crosslinking process in material 


what interpretes time. These differences correspond with the gelation time, the time, when the first 3D network is created in the whole volume of a sample. The lower temperature exerts influence upon the later achievement of gelation time. Crosslinking is significantly slowed down at the temperature slightly below $15^{\circ} \mathrm{C}$. The experiments also show a stillstand of the process at temperatures below $5^{\circ} \mathrm{C}$.

Further research of the crosslinking process of epoxy resins via Raman spectroscopy is going to be performed for higher temperatures in the range from 50 to $150^{\circ} \mathrm{C}$ using a new additional thermal chamber. Raman spectroscopy brings advantages of fast and specific analyses of structural changes without sample degradation or its surface disruptance. One of possible application of this method could be monitoring epoxy prepregs during their storage and subsequent use.

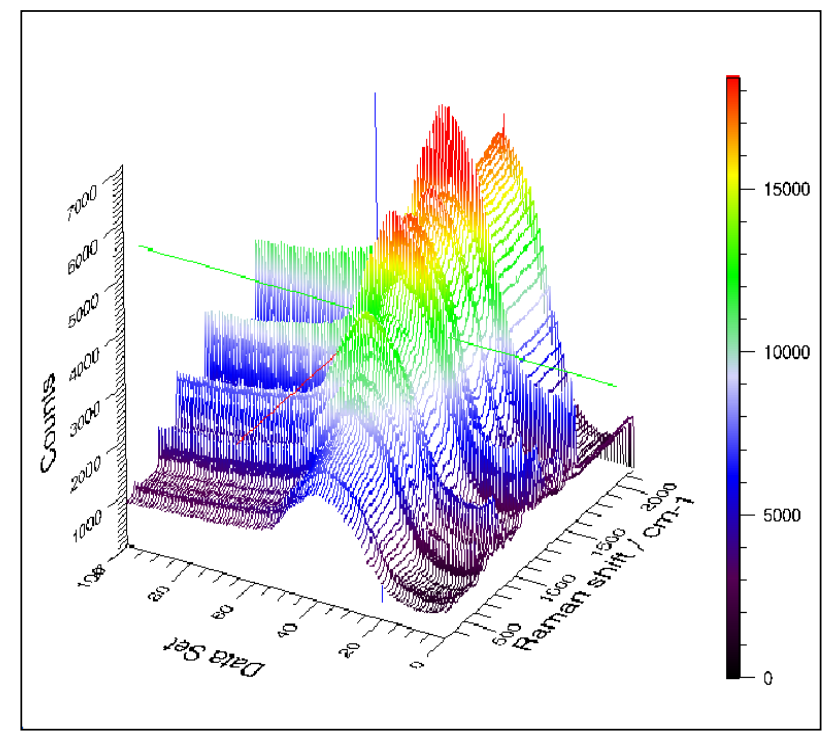

Fig. 6. 3D map of the crosslinking process of epoxy resin at $30^{\circ} \mathrm{C}$

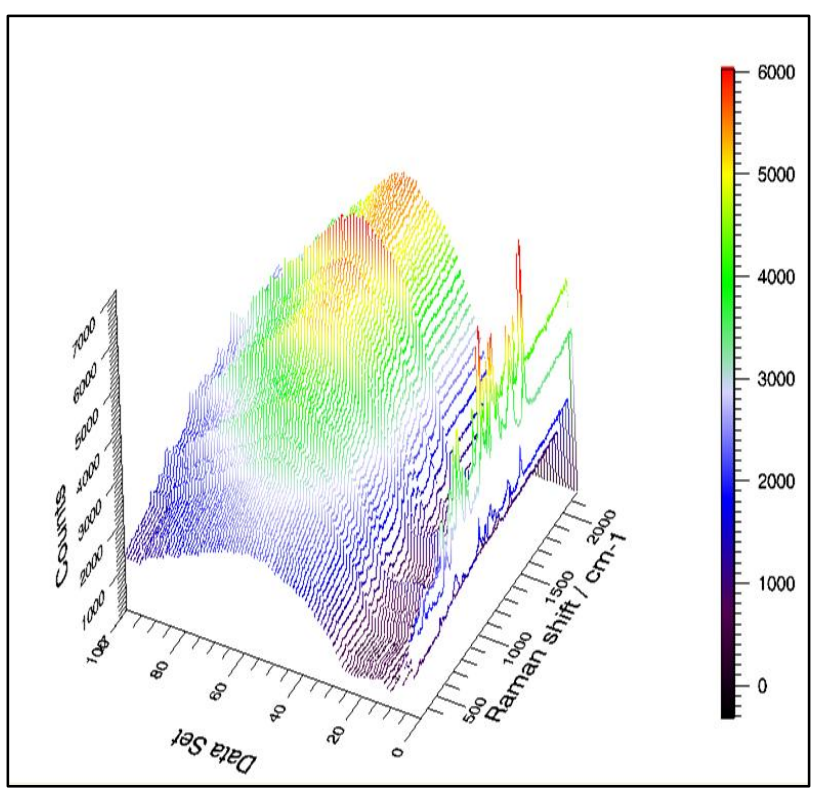

Fig. 7. 3D map of the crosslinking process of epoxy resin at $25^{\circ} \mathrm{C}$

\section{CONCLUSION}

By a reason of its nature, advantages and certain kind of innovatory, Raman spectroscopy has been chosen for the study of crosslinking process of the epoxy resin. The principal chemical bonds were identified, localised in Raman spectra and their behavior was studied in time. This technique appears to be valid and can be assessed as an efficient because it has the capability of an access to the control of quasi real time in-situ studies of crosslinking reaction and gives information on its kinetics.

The results are worthy for the purpose of monitoring during the epoxy based materials manufacturing. Another possible application can perform Raman spectroscopy as a quality control method using optical fibre probes for remote analysis, what can extend the applicability of spectroscopic method.

\section{ACKNOWLEDGEMENTS}

This work is supported by the Ministry of Education, Youth and Sports of the Czech Republic, by European Regional Development Fund under the project CEBIATech No. CZ.1.05/2.1.00/03.0089. The work is also supported by Internal Grant Agency of Tomas Bata University in Zlin under the project No. IGA/FAI/2012/056.

\section{REFERENCES}

[1] Vaskova, H., Manas, D., Ovsik, M., Stanek, M., Manas, M. Instrumented Microhardness Test and Raman Spectroscopz analyses of Beta-Irradiated Polyamide 12.In: 13th WSEAS International Conference on Systems (CSCC'12), Kos, Greece, 2012, pp. 329-332. WSEAS Press, ISBN: 978-1-61804-108-1

[2] M. Manas, M. Stanek, D. Manas, M. Danek, Z. Holik. Modification of polyamides properties by irradiation. Chemicke listy. Vol. 103, 2009, p.24-26

[3] Mizera, A., Manas, M., Manas, D., Stanek, M., Cerny, J., Bednarik, M., Ovsik, M. Modification of Polymer Poperties by Irradiation of HDPE after Radiation Cross-linking. In: $16^{\text {th }}$ WSEAS International Conference on Systems (CSCC'12), Kos, Greece, 2012, pp. 299-302. WSEAS press, ISBN: 978-1-61804108-1

[4] http://sunilbhangale.tripod.com. Tripod, Epoxy Resins. Accessed on: 2012-02-03

[5] Rocks, J.; Rintoul, L. \&Vohwinkel, F. (2007). The kinetics and mechanism of cure of an amino-glycidyl epoxy resin by a co-anhydride as studied by FT-Raman spectroscopy. Polymer international, Vol. 20, 2004

[6] Vaskova, H.. Raman spectroscopy: a modern technique for material properties identification. In: Proceedings of the $21^{\text {st }}$ International DAAAM Symposium 2010 in Zadar, Croatia. Vienna, 2010, pp. 1321-1322

[7] Hollas, J.M. (2004). Modern spectroscopy, 4th ed. J.Wiley\& Sons Ltd. England

[8] Colthup, N. B.; Daly, L.H., Wiberley, S. E., (2010).Introduction to Infrared and Raman Spectroscopy. Lightning Source UK, Ltd

[9] Lin-Vien, D.;Colthup, N.B. \&Fateley, W.G. (1991).The Handbook of IR and Raman Characteristic Frequencies of Organic Molecules. Academic Press, Boston, MA

[10] Lyon, R. E.; Chike, K. E. \&Angel, S. M. (1994). In-situ cure monitoring of epoxy resins using fibre-optic Raman spectroscopy. Journal of Applied Polymer Science, Vol. 53 